\title{
ПРОБЛЕМА УТИЛИЗАЦИИ ПЛАСТИКОВЫХ ОТХОДОВ
}

\author{
E. B. Потапова \\ Иркутский государственный университет, г. Иркутск, Российская Федерация
}

Информация о статье

Дата поступления

26 августа 2018 г.

Дата принятия к печати

9 ноября 2018 г.

Дата онлайн-размещения 27 декабря 2018 г.

\section{Ключевые слова}

Пластмассы; глобальная проблема; мусор; утилизация; экологизация

\begin{abstract}
Аннотация
Отходы, мусор представляют собой смесь веществ, предметов и их частей, потерявших потребительские свойства в процессе использования и предназначенных для удаления. Цель статьи отметить основные актуальные концепты проблемы распространения, утилизации пластиковых отходов и предложить ее перспективные решения. В России количество твердых коммунальных отходов составляет 63 млн т в год (около 450 кг на человека), из них до 25 \% может приходиться на пластик. Пластики - органические материалы, основу которых образуют синтетические или природные полимеры, состоящие из мономерных звеньев, соединенных в длинные макромолекулы. Самыми распространенными пластмассами являются поливинилхлорид, полиэтиленресталан, полипропилен, поликарбонат, полистирол, полиэтилен низкого и высокого давления и др. Для обеспечения утилизации одноразовых предметов разработана система маркировки, идентификационных кодов. Большинство типов пластмасс обычно хорошо поддается переработке и вторичному использованию. В Европе вторичной переработке подвергается до 50 \% отходов, а в России - не более 4 \%. Жизненный цикл пластика значительно превышает срок его службы. Так или иначе, весь пластик попадает на свалки, где продолжается его атака на природу и движение по пищевым цепям до человека. До 10 \% пластиковых отходов заканчивает свой путь в водах Мирового океана. Долговечный и нередко токсичный материал становится причиной заболеваний и гибели многих представителей наземной и водной фауны. Классическая иерархия управления отходами сводится лишь к трем векторам: утилизация, в том числе энергетическая, вторичное использование и переработка. Все они не являются оптимальными, особенно для окружающей среды. Стоит признать, что помимо прочего актуальным представляется путь оценки жизненного цикла пластика и экологизация общественного сознания в контексте уменьшения его потребления.
\end{abstract}

\section{THE ISSUE OF PLASTIC WASTE UTILIZATION}

\author{
Elena V. Potapova \\ Irkutsk State University, Irkutsk, the Russian Federation
}

\section{Article info}

Received

August 26, 2018

Accepted

November 9, 2018

Available online

December 27, 2018

\begin{abstract}
Waste or garbage is a mix of substances, objects and their parts that have lost their customer properties due to being used and so they are refused. The paper is aimed at characterizing main topical concepts of the problem of plastic waste spread and its utilization and suggesting its future solutions. In Russia the amount of solid municipal waste reaches $63 \mathrm{mln}$ tons per year (i. e. about $450 \mathrm{~kg}$ per person), up to $25 \%$ of it being plastics. Plastics are organic materials made of synthe-
\end{abstract}




\section{Keywords}

Plastics; global issue; garbage; utilization; greening sized or natural polymers consisting of monomer units that are joined together to form long macromolecules. The most widespread types of plastic are polyvinyl chloride, polyethylene terephthalate, polypropylene, polycarbonate, polystyrene, low and high density polyethylene (LDPE and HDPE), etc. A system of identification codes and labeling was developed to facilitate utilization of disposable items. The majority of types of plastic can be easily reprocessed and recycled. In European countries, up to $50 \%$ of waste is recycled while in Russia this number does not exceed $4 \%$. The life cycle of plastic is much longer than its useful life. One way or another, all plastic items get into landfills where plastic goes on affecting the environment and moves along the food chains up to humans. Up to $10 \%$ of plastic waste ends up in the World Ocean. This durable and often toxic material results in diseases and death of many terrestrial and aquatic animals. The classic waste management hierarchy is limited to three major directions: disposal (including energy recovery), recycling and reuse, all of which being not optimal particularly in respect of the environment. It should be recognized that, among other issues, plastic life cycle assessment and raising public awareness of a need to minimize use of plastic are relevant ways out. отходов. Помимо этого, по данным крупнейшего участника рынка ТКО — госкорпорации «Ростехнологии», в стране на стихийных свалках скопилось свыше 31 млрд т неутилизированных отходов ${ }^{3}[1]$. Приходится констатировать, что приведенные в статье данные, в том числе из государственных докладов РФ, носят весьма спорный и лишь оценочный характер из-за сложностей в переучете отходов, образовавшихся десятилетия назад, а также в их доучете на вновь выявляемых неорганизованных свалках. Имеются серьезные проблемы, связанные с объективным отражением последствий разложения, выветривания, зарастания растительностью и т. п. ранее накопленных отходов. Как следствие, статистические сведения об их образовании и движении как для мирового сообщества, так и для России чрезвычайно неточные и неполные. В государственном докладе «О состоянии и об охране окружающей среды Российской Федерации в 2016 году» отмечено, что общая величина накопленных и учтенных отходов производства и потребления в целом по стране составляла на конец 2015 г. примерно 31,5 млрд т, а на конец 2016 г. порядка 40,7 млрд т.

Отходы представляют собой гетерогенную смесь, в связи с чем они систематизированы на десять классификационных групп. В первую очередь отходы разделяют на промышленные и коммунальные (бытовые),

3 Проблема отходов : проект Гринпис. URL: http://www.greenpeace.org/russia/ru/campaigns / ecodom/lables ; Разработка концепции управления ТБО в туристической зоне озера Байкал, 2006-2008 гг. Раздел публикации: программа Европейской комиссии Tempus IV. 
затем по агрегатному состоянию - твердые и жидкие, по величине фракций, в миллиметрах, по химическому составу, по физическим и санитарно-бактериологическим свойствам и даже по времени образования.

По морфологическому признаку выделяют более десяти основных компонентов отходов, доля которых в общем объеме мусора зависит от страны, региона, климатической зоны, времени года, экономической ситуации, уровня благоустройства жилого фонда и др. (табл. 1).

Таблица 1

Примерный морфологический состав отходов

\begin{tabular}{|l|c|}
\hline \multicolumn{1}{|c|}{ Компонент } & $\begin{array}{c}\text { Доля в общей } \\
\text { массе, \% }\end{array}$ \\
\hline Пищевые отходы & $20-50(75)$ \\
\hline Бумага, картон & $25-40$ \\
\hline Стекло & $3-10$ \\
\hline Пластмасса & $2-10(40)$ \\
\hline Текстиль & $3-7$ \\
\hline Кожа, резина & $1-7$ \\
\hline Дерево & $1-4$ \\
\hline Камни & $1-3$ \\
\hline Кости & $0,5-4,0$ \\
\hline Металлы & $0,2-5,0$ \\
\hline Другое & $1-5$ \\
\hline
\end{tabular}

Составлена по данным: Пластик: реальная угроза. URL: http://www.nat-geo.ru/planet-or-plastic /1201321-plastik-realnaya-ugroza ; Пластик: проклятие мирового океана. URL: http://www.nat-geo.ru/ planet-or-plastic / 1200843 -plastik-proklyate-mirovogo-okeana/\#full ; Разработка концепции управления ТБО в туристической зоне озера Байкал, 2006-2008 гг. Раздел публикации: программа Европейской комиссии Tempus IV. URL: http://www.tiwasic.de/rus/publications.html ; Проблема отходов : проект Гринпис. URL: http: //www.greenpeace.org/russia/ru/campaigns / ecodom/lables; Борьба с пластиком: мировой опыт. URL: https://praktika.ru ; События, фракты // Твердые бытовые отходы. 2017 . № 7 (133). С. 3-7 ; Plastics Europe. URL: https://www.plasticseurope.org/en ; [1].

Согласно Федеральному закону «Об отходах производства и потребления» № 89Ф3, отходы в зависимости от степени негативного воздействия на окружающую среду в соответствии с критериями, установленными федеральным органом исполнительной власти, осуществляющим государственное регулирование в области охраны окружающей среды, подразделяются на пять классов опасности: от I - чрезвычайно опасные до $\mathrm{V}$ - практически неопасные.

Цель статьи - отметить основные актуальные концепты проблемы накопления, распространения и утилизации пластиковых отходов и предложить ее перспективные решения.

\section{Общие сведения}

Пластмассы или пластики - органические материалы, основу которых образуют синтетические или природные высокомолекулярные соединения - полимеры, состоящие из мономерных звеньев, соединенных в длинные макромолекулы химическими или координационными связями. Именно синтетические полимеры лидируют по производству, распространению и потреблению, а также становятся одной из глобальных проблем современности, поскольку интенсивно загрязняют, засоряют Землю. Эти материалы дешевы, их легко изготовить, им можно придать практически любую форму - листы, пленки и тончайшие нити. Пластики характеризуются высокой химической стойкостью к кислотам и щелочам, не пропускают воду, устойчивы к коррозии, плохо проводят электрический ток и тепло. В мире выпускается огромное количество типов синтетических полимеров. Самыми распространенными пластмассами являются: поливинилхлорид (ПВХ); полиэтиленрефталан (ПЭТ); полипропилен (ПП); поликарбонат (ПК); полистирол (ПС); полиэтилен низкого давления (ПЭНД); полиэтилен высокого давления (ПЭВД); полиэтиленовый воск (ПВ0; полибутилентерефталат (ПБТ); полиамид (ПА); акрилонитрилбутадиенстирол (АВС). В настоящее время база синтетических полимерных материалов доходит до 100 тыс. наименований ${ }^{4}[2 ; 3]$.

Пакет из полиэтилена впервые был изготовлен в США в 1957 г. С середины XX в., когда начался промышленный выпуск пластика, на планете произвели более 8 млрд т этого материала. Промышленность в год производит более 300 млн т пластика. Всего за несколько десятков лет потребление пластиков увеличилось с 5 млн до 100 млн т в год, и около половины его общего объема появилось за последние 15 лет [2-4]. Пластик - самый производимый продукт на планете Земля. Ее население использует почти 1 млн пластиковых бутылок каждую минуту! Но только менее 25 \% бытового пластика в мире отправляется на переработку, а в некоторых регионах он не перерабатывается вообще 5 . Дешевизна, легкость и прочность материала позволили ему быстро распро-

${ }^{4}$ Разработка концепции управления ТБО в туристической зоне озера Байкал, 2006-2008 гг. Раздел публикации: программа Европейской комиссии Tempus IV ; Борьба с пластиком: мировой опыт. URL: https://praktika.ru ; Plastics Europe. URL: https://www.plasticseurope.org/en.

5 Пластик: реальная угроза ; Пластик: проклятие мирового океана. 
страниться по всему миру, и к настоящему времени это самый часто встречающийся вид мусора.

В 1988 г. в США Общество пластмассовой промышленности (Society of the Plastics Industry) для обеспечения утилизации одноразовых предметов разработало систему маркировки (коды переработки) для всех видов пластика и идентиорикационные коды (табл. 2).

Существует также седьмой класс для других видов пластика. Маркированное этой цифрой изделие не может быть переработано и заканчивает свой жизненный цикл на по- лигоне захоронения или в печи мусоросжигательного завода.

Поливинилхлорид практически не поддается переработке. Более того, существуют доказательства того, что содержащийся в нем канцероген винилхлорид обладает способностью проникать через продукты питания в организм человека. Для его производства используется множество химических добавок, токсичных для биосферы и человека: фталаты, тяжелые металлы и т. д. Процесс производства, использования и утилизации (сжигания) ПВХ сопровождается образованием

Таблица 2

Примеры некоторых базовых полимеров

\begin{tabular}{|c|c|c|c|c|c|}
\hline Класс & Пример & Название & $\begin{array}{c}\text { ГОСТ } 33366.1- \\
2015 \text { (ISO 1043- } \\
1: 2011)\end{array}$ & $\begin{array}{c}\text { ГОСТ } \\
24888-81\end{array}$ & $\begin{array}{c}\text { Знак кода } \\
\text { переработки }\end{array}$ \\
\hline 1 & $\begin{array}{l}\text { Бутылки для напитков, упаковки } \\
\text { для порошков и сыпучих пище- } \\
\text { вых продуктов, полиэстер }\end{array}$ & $\begin{array}{c}\text { Полиэтилен- } \\
\text { терефрталат } \\
\text { (лавсан) }\end{array}$ & PET & ПЭТФ & \\
\hline 2 & $\begin{array}{l}\text { Пакеты фасовочные, для соков } \\
\text { и молока, контейнеры для про- } \\
\text { дуктов, бутылки для шампуней, } \\
\text { отбеливателей }\end{array}$ & $\begin{array}{c}\text { Полиэтилен } \\
\text { высокой плот- } \\
\text { ности (низкого } \\
\text { давления) }\end{array}$ & PEHD (HDPE) & $\begin{array}{l}\text { ПЭНД } \\
\text { (ПНД, } \\
\text { ПЭВП) }\end{array}$ & \\
\hline 3 & $\begin{array}{l}\text { Окна, двери, мебель, наполь- } \\
\text { ные покрытия, банки для пище- } \\
\text { вых жиров }\end{array}$ & $\begin{array}{c}\text { Поливинилхло- } \\
\text { рид }\end{array}$ & PVC & ПВХ & \\
\hline 4 & $\begin{array}{l}\text { Пакеты, пищевая пленка, ведра, } \\
\text { трубы, крышки, гибкие пласти- } \\
\text { ковые упаковки }\end{array}$ & $\begin{array}{c}\text { Полиэтилен } \\
\text { низкой плотно- } \\
\text { сти (высокого } \\
\text { давления) }\end{array}$ & $\begin{array}{l}\text { PELD } \\
\text { (LDPE) }\end{array}$ & $\begin{array}{l}\text { ПЭВД } \\
\text { (ПВД, } \\
\text { ПЭНП) }\end{array}$ & \\
\hline 5 & $\begin{array}{l}\text { Посуда для горячих блюд, од- } \\
\text { норазовые шприцы, мешки для } \\
\text { упаковки круп, сахара, контей- } \\
\text { неры для замораживания про- } \\
\text { дуктов, бутылочные крышки, } \\
\text { бутылки для кетчупов и сиропов, } \\
\text { стаканчики для йогурта, детали } \\
\text { автомобилей }\end{array}$ & Полипропилен & PP & ПП & \\
\hline 6 & $\begin{array}{l}\text { Игрушки, упаковочные подносы } \\
\text { для продуктов, одноразовая } \\
\text { посуда, подложки, цветочные } \\
\text { горшки, чемоданы, баночки для } \\
\text { лекарств }\end{array}$ & Полистирол & PS & $\Pi С$ & \\
\hline
\end{tabular}

"Использованы изображения знаков с сайта Greenpeace.org. См.: Проблема отходов : проект Гринпис. 
диоксинов (опасных ядов) и других крайне токсичных химических веществ. Остальные типы пластмасс обычно хорошо поддаются переработке и вторичному использованию 6 [4].

Согласно Федеральному классификационному каталогу отходов, пластик относится к IV и V классам опасности, т. е. это малоопасный и практически неопасный тип отходов. Но он наносит серьезный, плохо прогнозируемый, замедленный ущерб окружающей среде. При его производстве используется огромное количество воды, в атмосферный воздух выделяется до 400 млн т углекислого газа в год, а основной проблемой считается его утилизация. Жизненный цикл пластика значительно превышает срок его службы. Так или иначе, весь пластик попадает на полигоны, где продолжается мусорная пластиковая атака на природу и начинается его путь по пищевым цепям.

\section{Пластик в биосфере}

Долговечный и нередко токсичный материал становится причиной заболеваний и гибели многих представителей наземной и водной фауны. До 10 \% пластиковых отходов заканчивает свой путь в водах Мирового океана, 88 \% поверхности которого уже загрязнено пластиковым мусором различного размера, а наиболее мелкие частицы оседают в пищеварительной системе морских обитателей ${ }^{7}$. По данным ученых, в желудках $94 \%$ птиц и $86 \%$ черепах можно найти пластик. Исследователи обнаружили микропластик во внутренностях 114 видов водных животных. Больше половины из них человек употребляет в пищу [5; 6]. Один пакет может убить много раз. Более 260 видов животных, в том числе беспозвоночных, либо случайно проглатывают пластик, либо запутываются в нем. Запутанность обычно приводит к смерти или тяжелым травмам. Подсчитано, что более 400 тыс. морских млекопитающих погибает ежегодно в результате пластикового загрязнения океанов. Уже в 2004 г. зафиксировано, что чайки в Северном море имели в среднем по 30 кусков пластика в своих желудках [7; 8]. В верхнем слое воды океана в шесть раз больше пластика, чем планктона. Он не тонет и плавает всего в нескольких сантиметрах от поверхности воды, привлекая рыб, которых далее едят другие животные. Все участники цепочки чаще всего отравляются или погибают. На глубинах более километра концентрация мусора составляет от 17 до

\footnotetext{
6 Пластик: реальная угроза ; Пластик: проклятие мирового океана.

7 Там же.
}

335 единиц на квадратный километр. На дне Марианской впадины лежат пакеты и банки ${ }^{8}$.

В наземных экосистемах протекают сходные процессы: от мелких почвенных организмов, червей через цепи питания пластик доходит до крупных животных и человека. Примерно 800 видов животных сегодня находится под угрозой вымирания из-за поедания пластика и отравления им [9-11].

То, чем ценен пластик для людей, - легкость и долговечность - усиливает его опасность для природы. У него есть потенциал войти в глобальную продовольственную сеть по трофическим цепям. Люди тоже часть этой пищевой цепи. В сети рыбаков давно попадается больше пластика, чем рыбы. Химики из университета в Эдинбурге открыли, что рыбы и животные, которые «питаются» пластиком, являются не единственным и даже не основным источником пластика в пище человека. Это может быть оседающая на ней пыль. За 20 минут в еду с пылью может попадать около 14 частиц пластмассы [6].

Пластики различаются по содержанию целого ряда добавок, которые могут проникать в окружающую среду, аккумулироваться в ней и оказывать на нее синергетический эффект. Некоторые из этих химикатов считаются эндокринными разрушителями, вызывающими гормональные сбои. Например, они могут нарушать развитие мозга ребенка в утробе матери. Другие соединения, содержащиеся в пластике, способны вызывать врожденные патологии, рак и обладают тератогенным эффектом9. Хлорированный пластик выделяет в почву вредные химические вещества, что отравляет в том числе и источники воды. С другой стороны, по уровню отрицательного воздействия многих из пластмасс на лабораторных животных они считаются безопасными для людей, в связи с чем их давно применяют для изготовления различных имплантов (например, зубы, кости и др.).

\section{Существующие решения проблемы утилизации пластика}

Проблема рециклинга отходов полимерных материалов обретает актуальное значение не только с позиции охраны окружающей среды, она также связана с тем, что в условиях дефицита сырья пластмассовые отходы становятся мощным сырьевым и энергетическим ресурсом. Использование

${ }^{8}$ Пластик: реальная угроза ; Пластик: проклятие мирового океана.

9 Пластик: реальная угроза ; Пластик: проклятие мирового океана ; Проблема отходов : проект Гринпис ; Борьба с пластиком: мировой опыт ; Plastics Europe. 
отходов полимеров позволяет существенно экономить первичное сырье (прежде всего нефть), воду и электроэнергию.

Выбор схем технологической переработки пластиковых отходов обусловлен их физико-химическими, механическими и технологическими свойствами, временем использования и «старения» (изменение, ухудшение структуры и состава полимерного компонента под действием эксплуатационных фракторов), которые в значительной степени отличаются от тех же характеристик первичного полимера.

Классическая иерархия управления отходами, которая является основой разрабатываемых стратегий по сокращению количества отходов, сводится лишь к трем векторам:

- утилизация, в том числе энергетическая (сжигание на мусоросжигательных заводах), т. е. их правильный сбор и размещение;

- вторичное использование тех же изделий;

- переработка, или рециклинг (механическими и физико-химическими методами) ${ }^{10}$.

Но ни один из этих способов не приводит к безопасному для природной среды и здоровью человека действительному уничтожению, удалению пластиковых отходов и отходов их сжигания.

Актуальным базовым решением проблемы накопления пластика является уменьшение (до полного исключения) использования некоторых типов товаров, преимущественно одноразовых, и рециклинг других. В Европе еще в 2006 г. переработка пластмасс, включая и механический рециклинг, и получение топлива за счет утилизации отходов, превысила 50 \% [2]. Но проблема далека от решения, особенно в глобальном масштабе, в связи с чем распространяются и другие меры.

Так, во Франции с 2017 г. действует запрет на использование одноразовых пластиковых пакетов во всех типах магазинов, рынков и аптек. Производители продукции до 2017 г. еще могли упаковывать товар в полиэтилен, но не плотнее 50 микрон $^{11}$ [3]. В Ирландии запрещено выдавать полиэтиленовые пакеты бесплатно, на них установлены высокие налоги и цены. В Германии посетителям предлагают бумажные пакеты и тканевые сумки вместо полиэтилена. Кроме природоохранной, проводится и просветительская работа. В Дели, где от пластика гибнут бродячие коровы, введен запрет на производство, продажу и использование упаковочной пленки и полиэтиленовых пакетов, кроме пакетов для медицинских отхо-

\footnotetext{
${ }^{10}$ Plastics Europe.
}

11 lbid. дов. Более пяти лет назад подобный запрет выпустило правительство острова Занзибар, куда ранее ввозилось около 350 т пластиковых пакетов ежегодно. В настоящее время более 40 государств ограничивает использование пластиковой тары. Самый суровый закон принят в Кении, где под запретом выпуск, импорт и использование неразлагающихся пакетов. Нарушителям грозит штраф до 40 тыс. дол. США и тюремное заключение сроком до четырех лет ${ }^{12}$ [3]. К 2020 г. в Сан-Франциско (США) вводится запрет на напитки в пластиковой таре. Подобные законы уже действуют в 14 национальных парках и университетах США.

Для некоторых стран мусоропереработка стала многомиллиардным бизнесом. Это Германия, Яппония, Китай, Швеция, Великобритания и США. Две последние страны экспортируют огромные объемы своих отходов в Китай, который использует их как вторичное сырье. Около 30 \% вторичного пластика в мире идет на изготовление синтетического волокна, нитей для ковров, одежды. Остальные направления включают производство листа, пленки, бандажной ленты, обивки для автомобилей. До 70 \% всего вторичного ПЭТ в Европе перерабатывают в волокна полиэстера, используемого как утеплитель одежды, спальных мешков, наполнитель для мягких игрушек. Из волокон меньшего диаметра получают искусственную шерсть для одежды. Такие ткани могут содержать до 100 \% вторичного материала. Например, для изготовления свитера из искусственной шерсти требуется около 25 переработанных ПЭТ-бутылок [12].

Созданный компанией Envion генератор (Envion Oil Generator) способен перерабатывать 10 тыс. т пластикового мусора ежегодно, выдавая при этом до 50 тыс. баррелей синтетической нефти. Этот метод позволяет переработать в жидкое топливо до $82 \%$ пластика, а стоимость переработки в синтетическое топливо составляет приблизительно 17 дол. за тонну.

В Европе строят предприятия по производству дизтоплива из пластиковых отходов, пластик добавляют в битум и другие изделия для дорожного покрытия. Несколько лет назад голландские ученые предложили концепцию Plastic Road - пластиковых дорог. Автомобильная трасса будет собираться из пластиковых модулей, выдерживающих такую же нагрузку, как асфальт. При этом они более легкие, чем обычные покрытия,

${ }^{12}$ События, факты // Твердые бытовые отходы. 2017. № 7 (133). . C. 3-7. 
и почва меньше подвержена оседанию, их проще транспортировать. Этот материал отличается дешевизной, долговечностью и быстротой создания из него различных конструкций. После окончания срока службы модули можно перерабатывать и вновь использовать [13].

В России развернута реформа государственного регулирования обращения с отходами производства и потребления с целью придания этому регулированию системности, обеспечения прозрачности процесса и повышения эфффективности обращения с отходами. В первую очередь это касается ТКО. Фактически только предполагается сформировать новую отрасль, которая обеспечит охрану окружающей природной среды и более рациональное использование ресурсов. В целом вопрос рециклинга не только пластикового, но и других типов отходов, пригодных для вторичной переработки, у нас решается очень медленно и в основном на бумаге.

В июле 2018 г. Комитет по культуре Ленинградской области запретил использование пластиковой посуды, полиэтиленовых пакетов и упаковки при проведении культурно-массовых мероприятий. Это самое передовое для нашей страны решение. В Иркутской области до сих пор не разработана региональная программа, а территориальная схема обращения с отходами решением суда по иску прокурора области признана незаконной и отменена. При этом расположенные в границах центральной экологической зоны озера Байкал полигоны ТБО не отвечают практически никаким предъявляемым требованиям. В Республике Бурятия только после прокурорского реагирования муниципальными образованиями разработаны проекты строительства 11 полигонов. Экспертный совет при Правительстве России в марте 2018 г. выступил с инициативой запретить продажу пластиковых пакетов на побережье Байкала. Еще осенью 2016 г. были предложения ввести запрет на полиэтиленовые пакеты и одноразовую пластиковую посуду в заповедниках, заказниках и национальных парках РФ, но вопрос так и не решен. На острове Ольхон начата реализация негосударственного (волонтер выиграл грант) проекта по раздельному сбору мусора, но его дальнейший путь однозначно не определен.

Утилизация начинается с сортировки мусора. Даже пластик необходимо разделять по типам. Этот первичный этап работы с отходами в России за редким исключением отсутствует, и многие местные попытки по его внедрению терпят неудачи - население отказывается выполнять даже простое разделение. Появились предприниматели (некоторые работают более 20 лет), принимающие отдельные виды пластиковых отходов (например, бутылки без крышек и этикеток), но редко кто из них занимается их вывозом, лишь при значительных объемах, а цена пластика обычно не превышает 10 р. за килограмм, т. е. население мало заинтересовано в процессе. Многие регионы РФ, где еще не построены мусоросжигательные заводы, планируют возведение таких объектов, несмотря на все протесты экологических организаций и даже жителей, связанные в основном с тем, что атмосферный воздух практически всех крупных городов России загрязнен настолько, что даже минимальная дополнительная нагрузка невозможна. Итог: в России полноценная утилизация (энергетическая и механическая) отходов, особенно пластиковых, может стать очень отдаленной перспективой.

\section{Заключение}

Срок использования некоторых видов пластиковой продукции - минуты, срок жизни - столетия. Если сложить всю выброшенную на Земле за один год пластиковую тару, то эта цепочка обернет земной шар четыре раза, при этом более 50 \% ее общего объема использовалось только однажды ${ }^{13}$.

Пластик переполняет свалки, летает в воздухе и даже в космосе, заполняет реки, озера и моря, загрязняет почву и тела организмов. Бум на пластик возник в 1950-х гг., и на данный момент ни одна произведенная в те времена вещь не исчезла естественным путем. Причем ученые считают, что пластик вообще не разлагается, а распадается на кусочки, которые со временем становятся все меньше, в результате попадают в организм человека с водой, воздухом и пищей. Дилемма заключается в противоречии между положительными свойствами пластика, его низкой ценой и экологическими проблемами, возникающими в результате засорения окружающей среды пластиковыми отходами, которые веками не разлагаются.

Пластиковый мусор - глобальная проблема современности, вызванная экспоненциальным ростом его производства и накопления. Несмотря на то что этот вид отходов законодательно является малоопасным для окружающей среды и поддается переработке, бо́льшая часть пластика, особенно в России, складируется. Все существующие методы переработки пластика не уменьшают его

13 Пластик: реальная угроза ; Пластик: проклятие мирового океана ; Проблема отходов : проект Гринпис. 
количество на Земле, не способствуют его биоразложению, а при сжигании пластиковых отходов выделяются токсичные вещества, поэтому решение проблемы накопления пластикового мусора точно не определено.

Теоретически большинство пластиков легко подвергается вторичной переработке, необходимо лишь правильно организовать их сбор и сортировку. Экологически ответственные страны уже давно не только разделяют отходы, но и пытаются минимизировать использование пластика. Из торговых сетей исчезают полиэтиленовые пакеты, одноразовые вещи, создается система приема использованных пластиковых емкостей для их последующей переработки.

Основными направлениями обеспечения рационального и безопасного обращения с пластиковыми отходами являются: установление фредеральных и региональных норм и правил, направленных на обеспечение экономических, социальных и правовых условий для более полного использования отходов и уменьшения их образования; планирование и осуществление мер по предупреждению и ликвидации чрезвычайных ситуаций, возникших при обращении с отходами.

Для России безусловным первостепенным решением должна стать экологизация сознания населения, повышение уровня его знаний в данной области, а также разумное ограничение использования пластиков [14].

Кроме того, существуют процедуры, мало применяемые в нашей стране, - это стратегическая экологическая оценка (СЭО) и оценка жизненного цикла (ОЖЦ). СЭО это оценка вероятных экологических и социально-экономических последствий реализации различных сценариев долгосрочного развития. Она представляет собой успешно используемый в других странах методический инструмент, не только способствующий прогнозированию и планированию устойчивого и предынвестиционного развития, но и моделирующий возможности решения различных проблем с учетом региональных особенностей.

Оценка жизненного цикла предполагает сбор полноценной научной информации, сопоставление и оценку входных и выходных потоков производства и использования, а также возможных воздействий на окружающую среду на всем протяжении жизненного цикла продукции. ОЖЦ - один из ведущих инструментов современного экологического менеджмента, перспективный метод улучшения экологических аспектов продукции и сравнения альтернатив [15; 16].

Специальные условия хозяйствования и обращения с отходами необходимы для особо охраняемых территорий. При создании инновационных актуальных схем использования, сбора, утилизации и размещения отходов должны учитываться зональные и климатические особенности, а также уникальность таких мест, как Байкальская природная территория [17; 18].

Во многих проектах решения проблемы утилизации пластиковых отходов предлагаются альтернативы, в том числе экономически выгодные, социально безопасные, но без осознания жизненно важной необходимости и срочности решения данной проблемы уже следующие за нами поколения подвергнутся прямому воздействию пластиковой экспансии. Если мы не заменим пластик, то его полимерные цепочки станут частью нас.

\section{СПИСОК ИСПОЛЬЗОВАННОЙ ЛИТЕРАТУРЫ}

1. Думнов А. Д. Проблема твердых коммунальных отходов и статистика / А. Д. Думнов, А. А. Романов // Использование и охрана природных ресурсов в России. - 2016. - № 3 (147). - С. 80-90.

2. Pellow D. N. Garbage Wars: The Struggle for Environmental Justice in Chicago / D. N. Pellow, L. S.-H. Park. Cambridge : MIT Press, 2004. - 256 p.

3. Knoblauch J. A. The environmental toll of plastics [Electronic resource] / J. A. Knoblauch / / Environmental Health News. - 2009. - Mode of access: https: / / www.ehn.org/plastic-environmental-impact-2501923191.html.

4. Рахимов М. А. Проблемы утилизации полимерных отходов / М. А. Рахимов, Г. М. Рахимова, Е. М. Иманов / / Фундаментальные исследования. — 2014. - № 8-2. - С. 331-334.

5. Масленников С. И. Микропластик в океане - новые проблемы морского природопользования / С. И. Масленников, Г. Ф. Щукина, Ю. П. Назарец / / Рыбное хозяйство. - 2017. - № 3. - С. 33-37.

6. Gruchlik Y. Removal of organic micropollutants in waste stabilization ponds: a review / Y. Gruchlik, K. Linge, C. Joll // Journal of Environmental Management. - 2017. - Vol. 206. - P. 202-214. — DOI: 10.1016/j. jenvman.2017.10.020.

7. Recycling of plastic waste: Screening for brominated flame retardants (BFRs) / K. Pivnenko [et al.] / / Waste Management. - 2017. - Vol. 69. - P. 101-109. — DOI: https: //doi.org/10.1016/j.wasman.2017.08.038.

8. Biodegradation of sugarcane trash through use of microbially enhanced compost extracts / K. Shrestha [et al.] / / Compost, Science \& Utilization. - 2012. - Vol. 20, № 1. - P. 34-42.

9. Тепеева А. Н. Влияние локальных зон размещения отходов на дрожжевые сообщества городских почв / А. Н. Тепеева, А. М. Глушакова, А. В. Качалкин // Гигиена и санитария. - 2018. - Т. 97, № 1. - С. 50-53. 
10. Pachepsky Y. Scale and scaling in soils / Y. Pachepsky, R. L. Hill // Geoderma. - 2017. — Vol. 287. P. 4-30.

11. Milios L. Sustainability impact assessment of increased plastic recycling and future pathways of plastic waste management in Sweden / L. Milios, A. Esmailzadeh Davani, Y. Yu / / Recycling. — 2018. — № 3. - P. 33-50.

12. Оценка экологической безопасности термопластичных материалов на основе линейных полимеров / В. П. Дмитренко [и др.] / / Экология промышленного производства. - 2018. — № 1 (101). - С. 52-59.

13. Amit G. An overview on waste plastic utilization in asphalting of roads / G. Amit [et al.] // Journal of Engineering Research and Studies. - 2012. - Vol. 3, № 2. - P. 1-5.

14. Transformation of environmental problems in Moscow: sociological dimension / V. R. Bityukova [et al.] // Geography, Environment, Sustainability. — 2016. - Vol. 9, № 4. - P. 77-91.

15. Korytny L. M. Floods in east Siberia: damage and risks wit / L. M. Korytny, N. V. Kichigina / / Transactions on Ecology and the Environment. - 2011. - Vol. 146. - P. 95-104.

16. Evseev A. V. "Green» development of the Ugra territory: options and obstacles / A. V. Evseev, T. M. Krasovskaya, A. A. Medvedkov / / Geography, Environment, Sustainability (GES Journal). - 2017. - Vol. 10, № 2. - P. 94-102. — DOI: 10.24057 / 2071-9388-2017-10-2-94-102.

17. Zabortseva T. Modern economic and geographical characteristics and prospects of development of environmental protection infrastructure in the Baikal region of Russia / T. Zabortseva // Quaestiones Geographicae. - 2011. - Vol. 30, iss. 2. - P. 81-86.

18. Проблемы экологизации экономического развития региона с особым статусом природопользования / А. С. Михеева [и др.] / / Инженерная экология. - 2012. - № 4. - С. 42-49.

\section{REFERENCES}

1. Dumnov A. D., Romanov A. A. The Problem of Municipal Solid Waste and Statistics. Ispolzovanie $i$ okhrana prirodnykh resursov $v$ Rossii $=$ Natural Resources Utilization and Conservancy in Russia, 2016, no. 3 (147), pp. 80-90. (In Russian).

2. Pellow D. N., Park L. S.-H. Garbage Wars: The Struggle for Environmental Justice in Chicago. Cambridge, MIT Press, 2004. 256 p.

3. Knoblauch J. A. The environmental toll of plastics. Environmental Health News, 2009. Available at: https:// www.ehn.org/plastic-environmental-impact-2501923191.html.

4. Rakhimov M. A., Rakhimova G. M., Imanov E. M. Problems of recycling polymer wastes. Fundamental'nye issledovaniya $=$ Fundamental research, 2014, no. 8-2, pp. 331-334. (In Russian).

5. Maslennikov S. I., Zhirmunsky A. V., Nazarets Y. P. Microplastic in the ocean - the new challenges of marine nature management. Rybnoe khozyaistvo = Fisheries, 2017, no. 3, pp. 33-37. (In Russian).

6. Gruchlik Y., Linge K., Joll C. Removal of organic micropollutants in waste stabilization ponds: a review. Journal of Environmental Management, 2017, vol. 206, pp. 202-214. DOI: 10.1016/j.jenvman.2017.10.020.

7. Pivnenko K., Granby K., Eriksson E., Astrup T. F. Recycling of plastic waste: Screening for brominated flame retardants (BFRs). Waste Management, 2017, vol. 69, pp. 101-109. DOl: https://doi.org/10.1016/j.wasman.2017.08.038.

8. Shrestha K., Shrestha P., Walsh K. B., Harrower K. M., Midmore D. J. Biodegradation of sugarcane trash through use of microbially enhanced compost extracts. Compost, Science \& Utilization, 2012, vol. 20, no. 1, pp. 34-42.

9. Tepeeva A. N., Glushakova A. M., Kachalkin A. V. The impact of local zones of the waste storage on yeast communities in urban soils. Gigiena $i$ sanitariya = Hygiene and Sanitation, 2018, vol. 97, no. 1, pp. 50-53. (In Russian).

10. Pachepsky Y., Hill R. L. Scale and scaling in soils. Geoderma, 2017, vol. 287, pp. 4-30.

11. Milios L. A., Esmailzadeh Davani A., Yu Y. Sustainability impact assessment of increased plastic recycling and future pathways of plastic waste management in Sweden. Recycling, 2018, no. 3, pp. 33-50.

12. Dmitrenko V. P., Gorbachev S. I., Bulychev S. N., Manuylova N. B., Messineva E. M. Assessment of ecological safety of thermoplastic materials on the basis of the linear polymers. Ekologiya promyshlennogo proizvodstva= Industrial ecology, 2018, no. 1 (101), pp. 52-59. (In Russian).

13. Amit G., Zamare G., Renge V. C., Tayde S., Bharsakale G. An overview on waste plastic utilization in asphalting of roads. Journal of Engineering Research and Studies, 2012, vol. 3, no. 2, pp. 1-5.

14. Bityukova V. R., Savoskul M. S., Kirillov P. L., Koldobskaya N. A. Transformation of environmental problems in Moscow: sociological dimension. Geography, Environment, Sustainability, 2016, vol. 9, no. 4, pp. 77-91.

15. Korytny L. M., Kichigina N. V. Floods in east Siberia: damage and risks wit. Transactions on Ecology and the Environment, 2011, vol. 146, pp. 95-104.

16. Evseev A. V., Krasovskaya T. M., Medvedkov A. A. "Green» development of the Ugra territory: options and obstacles. Geography, Environment, Sustainability (GES Journal), 2017, vol. 10, no. 2, pp. 94-102. DOI: 10.24057/2071-9388-2017-10-2-94-102.

17. Zabortseva T. Modern economic and geographical characteristics and prospects of development of environmental protection infrastructure in the Baikal region of Russia. Quaestiones Geographicae, 2011, vol. 30, iss. 2, pp. 81-86.

18. Mikheeva A. S., Khandazhapova L. M., Bardakhanova T. B., Maksanova L. B., Puntsukova S. D. Issues of Greening the Economic Development of the Region of a Special Natural Resource Management Status. Inzhenernaya ekologiya = Engineering Ecology, 2012, no. 4, pp. 42-49. (In Russian).

\section{Информация об авторе}

Потапова Елена Владимировна - доктор сельскохозяйственных наук, кандидат биологических

\section{Author}

Elena V. Potapova - D. Sc. in Agriculture, Ph. D. in Biology, Professor, Hydrology and Natural Resource 
наук, профессор, кафедра гидрологии и природопользования, Иркутский государственный университет, 664033, г. Иркутск, ул. Лермонтова, 126, e-mail: e.v.potapova.isu@mail.ru.

\section{Для цитирования}

Потапова Е. В. Проблема утилизации пластиковых отходов / Е. В. Потапова // Известия Байкальского государственного университета. - 2018. - Т. 28, № 4. - C. 535-544. - DOI: $10.17150 / 2500-$ 2759.2018.28(4).535-544.
Management Department, Irkutsk State University, 126 Lermontov St., 664033, Irkutsk, the Russian Federation, e-mail: e.v.potapova.isu@mail.ru.

\section{For Citation}

Potapova E. V. The Issue of Plastic Waste Utilization. Izvestiya Baykal'skogo gosudarstvennogo universiteta $=$ Bulletin of Baikal State University, 2018, vol. 28, no. 4, pp. 535-544. DOI: 10.17150/2500-2759.2018.28(4).535544. (In Russian). 